\title{
The Evolution of the Health Status and Quality of Life of Heroin Addicts Treated with Methadone in the City of Tangier, Morocco
}

\section{Wafae Samlali Idrissi' ${ }^{1}$, Ahmed Omar Tohami Ahami' ${ }^{1}$, Tarik Ghaihlan², Fatima-Zahra Azzaoui ${ }^{3}$, Khaoula Mammad1}

\author{
${ }^{1}$ Equip of Clinical and Cognitive Neuroscience and Nutritional Health, Department of Biology, Faculty of Science, Kenitra, Morocco \\ ${ }^{2}$ Unit of Formation and Research of Pneumology, Center for Doctoral Studies SVS, Mohammed V Souissi University, \\ Rabat, Morocco \\ ${ }^{3}$ Laboratory of Biology and Health, URAC 34, Department of Biology, Faculty of Science Ben M’Sik, Hassan II University, \\ Casablanca, Morocco
}

Email: idrissi_wafae@hotmail.fr

How to cite this paper: Idrissi, W. S., Ahami, A. O. T., Ghaihlan, T., Azzaoui, F.-Z., \& Mammad, K. (2018). The Evolution of the Health Status and Quality of Life of Heroin Addicts Treated with Methadone in the City of Tangier, Morocco. Psychology, 9, 519-528.

https://doi.org/10.4236/psych.2018.94031

Received: February 11, 2018

Accepted: April 6, 2018

Published: April 9, 2018

Copyright $(0) 2018$ by authors and Scientific Research Publishing Inc. This work is licensed under the Creative Commons Attribution International License (CC BY 4.0).

http://creativecommons.org/licenses/by/4.0/

\begin{abstract}
Opiate substitution treatment with methadone (STM) is one of the most effective means of treating heroin addiction. It presents itself as a beneficial treatment for health, and insertion into work but also for the reduction of infectious risks and crime. Improving the quality of life of patients during treatment including social and relational life and somatic state has been considered by some research to be more important than abstinence from the substance itself. The objective of this study is to evaluate the effect of methadone treatment on the quality of life of 101 drug-addicted patients in a health center in Tangier city, including the possible improvement of their socio-professional, relational and somatic state, using the characters of the official questionnaires of request of cure and based on the multidisciplinary method of the ASI (Addiction Severity Index). Our questionnaire included a rubric for sociodemographic data and another one for the evaluation of the impact of this treatment on the somatic, socio-professional and relational state of the patients according to two periods: before and after the treatment, and according to the duration of the treatment. The results obtained showed an improvement in the somatic state including weight, sleep, nutritional status and socio-occupational and relational status after inclusion in treatment.
\end{abstract}

\section{Keywords}

Substitution Treatment, Methadone, Heroin, Addiction, Quality of Life, Opiate, Health Status 


\section{Introduction}

Opiate substitution treatment with methadone (STM) is currently one of the effective means of treating heroin addiction and the use of illicit drugs in parallel (Mattick, Breen, Kimber, \& Davoli, 2009). A range of public is not sufficiently aware of the effectiveness of this treatment, although it is beneficial for public health and work integration, for reducing the risk of HIV infection as well as for crime (Mark, \& Parrino, 1992). In particular, it helps improve the quality of life of patients regarding professional and family integration (Teoh Bing Fei et al., 2016). Despite the widely documented success in treating chronic drug dependence for more than twenty-five years, methadone maintenance treatment has survived tough years of inadequate funding and some negative public perception. Substitution treatments are usually under suspicion (General Accounting Office, 1990). The concept of opioid substitution came into being in France with the marketing authorization for Opioid Substitution Drugs (OSD) in the nineties as part of a risk reduction policy (Guignard et al., 2011).

The general objectives of these treatments are the prevention of somatic and psychiatric complications to opioid dependence, the promotion of the insertion of dependent patients into a care process including the management of psychiatric and/or somatic pathologies associated with the treatment of opioid dependence, also the contribution of heroin addicts to their social integration, as well as allowing those people to free themselves from the center of their existence on the effects of the deleterious research of the product and to recover all or part of their freedom and overall a better quality of life in thus reducing the various damages induced. Otherwise, these therapeutic strategies also respond to the expectations of society (Karila et al., 2008). At the national level, the phenomenon of heroin consumption exploded at the end of the eighties, especially in the cities of Tangier and Tetouan, and subsequently spread throughout the North and Northeast zones of the country Morocco that goes from Tangier to Nador. In Morocco, methadone maintenance program (MMP) started only in 2010 in three pilot sites that are Tangier, Rabat and Casablanca. The number of patients treated in Tangier was higher than that of the two other sites (Salhi, 2010).

Otherwise, the missions of the Specialized Centers for the Care of Drug Addicts are to provide medico-psychological care and social and educational support which includes assistance to integration or reintegration (Observatoire français des drogues et des toxicomanies, 2003); to promote the treatment of somatic disorders; to improve the physical condition of patients and their quality of life; to promote the resumption of paid or unpaid activity and to promote the restoration of family and friendships liaisons (Programme de maintenance à la méthadone au Maroc., 2008). However, some previous studies have shown that the quality of life of opioid-dependent patients considered the element the most affected compared to the population with chronic diseases and the general population (Millson et al., 2004).

The aim of this study is to evaluate the effect of methadone treatment on the quality of life of drug-addicted patients, including socio-professional, relational 
and somatic situations, as well as improving professional and relationship functioning with treatment duration.

\section{Material and Methods}

The questionnaire of our study was built according to the needs of the study which is based on the approach of the ASI (Addiction Severity Index), which is a multidimensional evaluation focused on the consumption of products taking into account aspects of the patient's daily life. It comprises four parts: the sociodemographic data of the patients, the somatic state, the family relations and the professional situation. The variables and modalities used in our questionnaires are the same introduced in official treatment request questionnaires that are used by the methadone prescribers listed in their medical records. Data entry and statistical study performed on the SpSS software. The quantitative data summarized by their mean value (+/- standard deviation) and (minimum value - maximum value). Qualitative data are expressed as class size (with percentages on available data). The analytic statistic was based on the association relation between the qualitative variables and the $\chi^{2}$ test was used for one degree of freedom. The statistical significance threshold chosen was $5 \%$ and $1 \%$.

Furthermore, it is a prospective study for evaluative purposes, conducted at the Hasnouna medical and psychological center (HMPC) in Tangier (North of Morocco) during the period between March 2013 and August 2013.The HMPC in Tangier opened in 2004, has received almost 5000 patients since its opening until 2013, 80\% of which are heroin users, the same center had reached 3946 heroin users and cocaine in May 2012 with more than 700 cases of total with drawal. The center had adopted two types of treatment for heroin addicts: conventional treatment and STM: Conventional treatment suspended at the MPC in 2013, STM began in early 2010 and included almost 300 patients by June 2013. The HMPC admitted 277 heroin addicts with or without polydrug. In addition to the daily dose of methadone, patients receive medical and psychiatric care under the supervision of a health care team: nurses, general practitioners, addictologists, and psychiatrists. The 101 patients participated in this study including 85 men and 16 women. The patients included in this study are patients attending the methadone substitution program, diagnosed with opioid dependence as described in the DSM-V, at least 18 years of age, with or without poly-addiction and with or without psychiatric comorbidity. They were chosen in a random manner according to their availability and voluntarism; they are met in individual interviews. Exclusion criteria include patients with intellectual disabilities or organic disease that obstructs conversation, those with instability: aggression, impulsivity/acute psychiatric co-morbidity and patients with difficulties in understanding the questionnaires. After a reminder of the purpose of the study, the collection of data was anonymous to ensure their confidentiality. Free and informed consent obtained for all patients included in the study. 


\section{Results}

The 101 patients participated in the interview including 85 men with a mean of: age of $(\mathrm{m}: 37 \pm 8)$, a weight $(\mathrm{m}=66.40 \pm 14.29)$ and 16 women with a mean of: age $(\mathrm{m}=27 \pm 6)$, and a weight of $(\mathrm{m}=65.70 \pm 10.89)$. The minimum age of patients is 22 years old and maximum is 65 years, with a mean of 35 years (Table 1 ).

According to the comparison between lifestyle before and after treatment, there is a decrease in lifestyle (lives alone/precariousness/Divorced) difference, versus an increase in lifestyle (family/spouse/children) (difference: 10.3\%, 5.7\%, $8.5 \%)\left(p<0.01, \mathrm{~K}^{2}=277.584\right)$.

The assessment of the employment situation shows, a decrease in the number of patients who were unemployed (taking into account those who have resigned or suspended work because of drugs and those who left school for the same reason),

Table 1. Sociodemographic characteristics of patients.

\begin{tabular}{|c|c|c|c|c|c|}
\hline & Effective (N) & Frequency (\%) & Mean \pm SD & Min & $\operatorname{Max}$ \\
\hline \multicolumn{6}{|l|}{ Sex } \\
\hline $\operatorname{Men}(\mathrm{M})$ & 80 & & & & \\
\hline Women (W) & 19 & & & & \\
\hline \multicolumn{6}{|l|}{ Hometown } \\
\hline Tangier & 89 & 88.11 & & & \\
\hline Others & 12 & 11.88 & & & \\
\hline \multicolumn{6}{|l|}{ Age } \\
\hline M & & & $37 \pm 6$ & & \\
\hline $\mathrm{W}$ & & & $27 \pm 6$ & & \\
\hline Total & & & 35 & 22 & 65 \\
\hline \multicolumn{6}{|l|}{ Level of studies } \\
\hline Illiterate & 3 & 2.97 & & & \\
\hline primary & 44 & 43.56 & & & \\
\hline secondary & 29 & 28.71 & & & \\
\hline High school & 19 & 18.81 & & & \\
\hline superior & 6 & 5.94 & & & \\
\hline \multicolumn{6}{|l|}{ Age of first use } \\
\hline$<20$ years & 80 & 79.20 & & & \\
\hline$>20$ years & 21 & 20.80 & & & \\
\hline Total (Age) & & & $17.60 \pm 4.20$ & 11 & 32 \\
\hline \multicolumn{6}{|c|}{ Duration of the treatment } \\
\hline$<1$ years & 29 & & & & \\
\hline $1-2$ years & 48 & & & & \\
\hline$>2$ years & 21 & & & & \\
\hline Daily dose (mg) & & & $72.13 \pm 22.84$ & 15 & 170 \\
\hline
\end{tabular}


(with $55.2 \%$ before and $33.3 \%$ after). Against an increase in continuous paid activities ( $8.6 \%$ before and $18.1 \%$ after) and intermittent paid activity, $(21.9 \%$ before and $35.2 \%$ after $)$ with $\left(p<0.01, \mathrm{~K}^{2}=173.366\right)$ (Table 2$)$.

Fifty-two out of 90 patients (58\%) had sleep disturbances after treatment, mainly with insomnia $(29,55.8 \%)$ and hypersomnia $(10,19.2 \%)$. anorexia was present in 28 cases $(73.7 \%)$ (Table 3 ).

The $49 \%$ of patients saw their somatic state (including weight, sleep, and nutritional status) improve, compared to $14.8 \%$ whose somatic state had decreased (Figure 1).

The shortest duration of treatment being between ( 2 months and 1 year) of treatment, there is an absence of patients with a treatment duration between ( 6 and 9 months) with a total of 29 patients, the most long being between (1 years

Table 2. lifestyle and socio-occupational situation before and after treatment.

\begin{tabular}{|c|c|c|c|c|c|c|}
\hline & \multicolumn{2}{|c|}{ Period Before treatment } & \multicolumn{2}{|c|}{ Period After treatment } & \multirow{2}{*}{$\mathrm{Khi}^{2} / \mathrm{ddl}$} & \multirow{2}{*}{$\mathrm{P}$ value } \\
\hline & Effective & Frequency & Effective & Frequency & & \\
\hline Lifestyle & & & & & $\begin{array}{c}\mathrm{K}^{2}=277.584 \\
\mathrm{ddl}=49 \\
\mathrm{~V} \text { de cramer } \\
=0.627\end{array}$ & $<0.001^{*}$ \\
\hline No response & 10 & 9.5 & 9 & 8.6 & & \\
\hline Livesalone/insecure & 34 & 32.4 & 14 & 13.3 & & \\
\hline Liveswithhisfamily & 25 & 23.8 & 35 & 34.3 & & \\
\hline alonewithchildren & 1 & 1 & 1 & 1 & & \\
\hline Liveswithspouseonly & 12 & 11.4 & 18 & 17.1 & & \\
\hline $\begin{array}{l}\text { Lives with spouse } \\
\text { and children }\end{array}$ & 5 & 4.8 & 14 & 13.3 & & \\
\hline Liveswithhisfriends & 1 & 1 & 2 & 1.9 & & \\
\hline Divorced & 13 & 12.4 & 7 & 6.7 & & \\
\hline Total & 101 & 96.2 & 101 & 96.2 & & \\
\hline $\begin{array}{l}\text { Situation socio } \\
\text { profession nelle }\end{array}$ & & & & & $\begin{array}{c}\mathrm{K}^{2}=173.366 \\
\mathrm{Ddl}=16 \\
\mathrm{~V} \text { of cramer } \\
=0.655\end{array}$ & $<0.001^{*}$ \\
\hline 1) No response & 10 & 9.5 & 9 & 8.6 & & \\
\hline 2) Unemployment & 58 & 55.2 & 35 & 33.3 & & \\
\hline 3) Student & 0 & 0 & 0 & 0 & & \\
\hline 4) Retirement & 0 & 0 & 1 & 1 & & \\
\hline 5) Unpaidinternship & 1 & 1 & 0 & 0 & & \\
\hline 6) Continuouspaidactivity & 9 & 8.6 & 19 & 18.1 & & \\
\hline 7) Intermittent paidactivity & 23 & 21.9 & 37 & 35.2 & & \\
\hline Total & 101 & 96.2 & 101 & 96.2 & & \\
\hline
\end{tabular}

*significant when $P<0.01$. 
Table 3. Sleep disorders and eating disorders in the treatment period.

\begin{tabular}{ccc}
\hline Types of disorders (Treatment period) & $\mathbf{n}$ & $\%$ \\
\hline Sleeping troubles & & \\
Yes = 52; No = 38; Total = 90 & & $55.8 \%$ \\
Insomnia & 29 & $19.2 \%$ \\
Hypersomnia & 10 & $5.8 \%$ \\
Parasomnia & 3 & $19.2 \%$ \\
Other: fluctuation & 10 & \\
Troubles alimentaire & & \\
Yes = 38; No = 51; Total = 89 & & $73.7 \%$ \\
Anorexia & & $10.5 \%$ \\
Bulimia & 28 & $7.9 \%$ \\
Functional colopathy & 4 & $5.3 \%$ \\
Others & 3 & \\
\hline
\end{tabular}

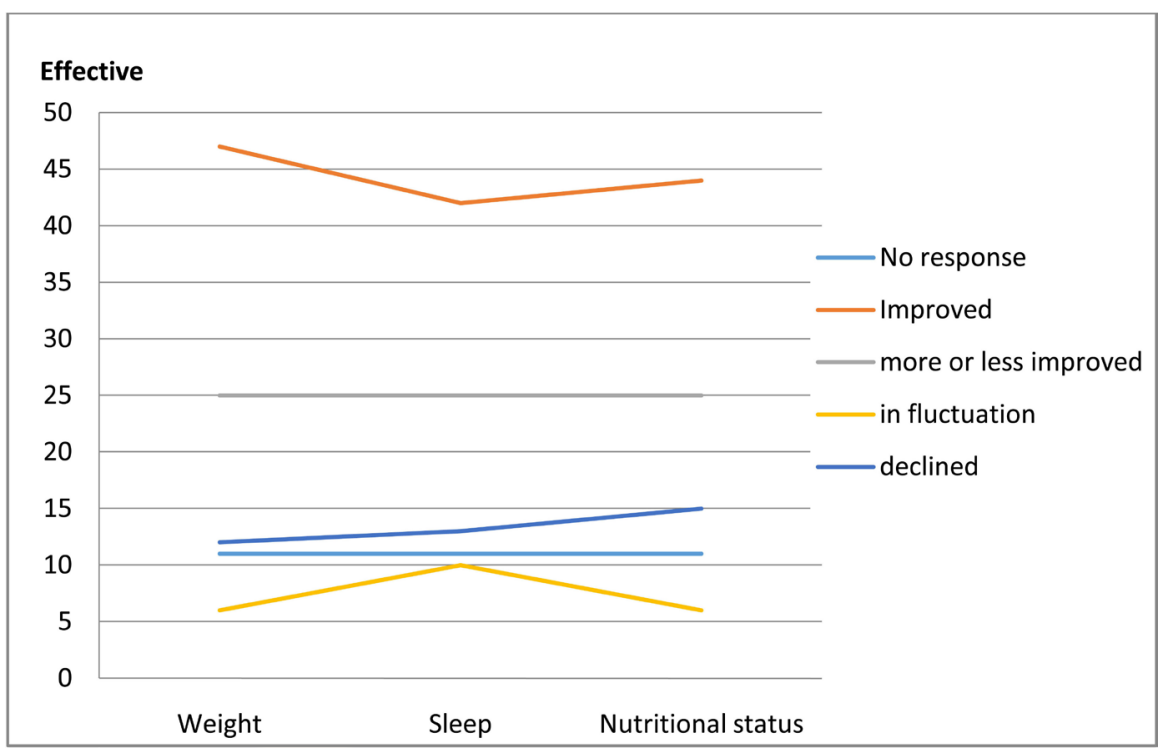

Figure 1. Improvement of the somatic state of patients after treatment.

and 9 months) and (more than 2 years) of treatment, with a staff of 33 patients. The results show an increase in intermittent paid activities and continuous paid activities in the shortest versus the longest duration. On the other hand, a decrease of unemployment profile between the two durations with $22.9 \%$ of difference is $\left(\mathrm{Khi}^{2}=92.11, \mathrm{ddl}=32 P<0.001\right)$. For the lifestyle after the treatment there is not a significant change which including (alone/Divorced/in precariousness) as well as for lifestyle including (in family/spouse) which did not present a remarkable change between the 2 duration of treatment with $\left(\mathrm{Khi}^{2}=\right.$ 126.454; ddl = 49; $P<0.001)$ (Table 4).

\section{Discussion}

Our study was able to address other aspects of opioid substitution treatment as 
Table 4. The relationship between the duration of treatment and the employment situation.

\begin{tabular}{|c|c|c|c|c|c|}
\hline & \multicolumn{3}{|c|}{ Professional situation after treatment } & \multicolumn{2}{|c|}{ LifestyleAftertreatment } \\
\hline & Unemployment & $\begin{array}{l}\text { Continuous } \\
\text { paid activity }\end{array}$ & $\begin{array}{l}\text { Intermittent } \\
\text { paid activity }\end{array}$ & Lives: alone/Divorced/in precariousness & Liveswithfamily/spouse \\
\hline $\begin{array}{l}\text { Duration of } \\
\text { the treatment }\end{array}$ & \multicolumn{3}{|c|}{$\mathrm{Khi}^{2}=92.11, \mathrm{ddl}=32, P<0.001^{*}$} & \multicolumn{2}{|c|}{$\mathrm{Khi}^{2}=126.454, \mathrm{ddl}=49, P<0.001 *$} \\
\hline+2 years & $17.1 \%$ & $35.3 \%$ & $20.5 \%$ & $16.00 \%$ & $2.94 \%$ \\
\hline $1.9 / 2$ & $8.6 \%$ & $11.8 \%$ & $17.9 \%$ & $17.52 \%$ & $16.18 \%$ \\
\hline $1.6 / 1.9$ & $0.0 \%$ & $0.0 \%$ & $5.1 \%$ & $13.00 \%$ & $13.24 \%$ \\
\hline $1.3 / 1.6$ & $17.1 \%$ & $23.5 \%$ & $7.7 \%$ & $10.00 \%$ & $1.47 \%$ \\
\hline 1 year $/ 1.3$ & $5.7 \%$ & $23.5 \%$ & $17.9 \%$ & $08.76 \%$ & $15.29 \%$ \\
\hline 9 month to 1 year & $14.3 \%$ & $0.0 \%$ & $20.5 \%$ & $11.29 \%$ & $28.06 \%$ \\
\hline 2 to 9 month & $34.3 \%$ & $5.9 \%$ & $7.7 \%$ & $20.57 \%$ & $14.71 \%$ \\
\hline No response & $2.9 \%$ & $0.0 \%$ & $2.6 \%$ & $2.86 \%$ & $9.12 \%$ \\
\hline TOTAL & $100 \%$ & $100 \%$ & $100 \%$ & $100 \%$ & $100 \%$ \\
\hline
\end{tabular}

* significant when $P<0.01$.

an indicator of the effectiveness of this program. this study carried out with 101 patients treated by STM in a medicopsychological-center in morooco have all eligibility for the PSM and have a duration of retention approximately between two moths till a four years of treatment, with a minimum age of 18 and a random sociodemographic criteria (Table 1). The latter has reflected some of the effectiveness of STM since the purpose of this treatment is not only the analysis of treatment domain factors and abstinence from drugs, but also deals with the overall medico-psychosocial care. Indeed, previous studies (Ball et al., 1991) have shown in the same context that several methods can be used to evaluate the efficacy of methadone treatment and that it can be measured by obtaining abstinence (cessation of non-prescribed opioid use), improving physical fitness, social reintegration and reducing crime (Giroux, 1999). Another study by Lalande and Grelet (2001) also addressed the impact of substitution on the patient's overall situation (social, emotional, health, etc.). Various studies have given importance to the evaluation of rehabilitation, and social inclusion during treatment, while in contrast they stated that abstinence is distinct from rehabilitation and that it is rather the latter that should be the indicator of a complete therapeutic approach to STM (Zweben \& Payte, 1990).

Our study has demonstrated that the majority of patients had an improvement after the treatment in their physical state including: (Weight, sleep, state of nutrition) (Figure 1). as well as an improvement of the professional and relational functioning during the retention in TSM this improvement had reflected a decrease in the percentages of some meaningful indicators like unstable state (lives alone/precariousness/divorced/unemployment), against a improvement of situations showing a stable state (Family /Spouse/Children/gainful activity con- 
tinues/gainful activity intermittent) (Table 2), another study conducted on 96 patients treated with methadone in Malaysia has shown an improvement of social functioning and physical symptoms. Also, patients who are maintained under treatment by methadone showed an improvement in the quality of life in all areas including the social relations and the state of physical health (Teoh Bing Fei et al., 2016).

Regarding the duration of retention in treatment, our study had not showed significant improvement in the relational and family State according to the duration of the treatment, contrariwise our study has revealed a significant improvement of the professional status in relation to the period of retention in treatment, since most of the patients maintained in a long duration of treatment have had a higher percentage of professional activities including the remunerated, intermittent and continuous activities. In The same context, the previous study of Malaysia carried out on 96 patients treated by methadone has shown that there is not a significant association of quality of life according to the period of treatment (Teoh Bing Fei et al., 2016).

In this study, the state of physical health including: Weight, sleep, state of nutrition has been declared improved by the majority of the patients (Figure 1), as well as Dr Mary Jeanne Kreek written in his own research that the Medical consequence the most important of the methadone maintenance treatment is the net improvement in the state of health and nutritional status observed in patients, (Mark \& Parrino, 1993).

Generally, our study like other studies with the same objective as the large cohort studies carried out in the United States who have studied the effects of treatments (methadone and other treatments) and long-term developments in subject drug addicts, the obtained results are more or less similar among these studies that have allowed us to demonstrate the effectiveness indisputable of the treatments in the addiction to drugs, also the improvement of the general situation of drug users when they persist in the circuits of care (Taïeb, 2006).

Despite our favorable outcome on the socio professional plan we cannot judge the overall efficiency of the TSM on the health of the patient, because there are a several indicators of evaluation as, the consumption of drugs by the intravenous means, and the risk behaviors that lead to infectious diseases, thus the criminal acts (Fullerton et al., 2014).

\section{Conclusion}

The improvement of the quality of life and the rehabilitation within the society as well as the improvement of health in general after a long duration of desorption of social links remain one of the objectives the more important of substitution treatment by methadone, so that the patient can achieve a total abstinence. This study has been able to show a positive evolution in a part of the state of health as well as the quality of life of the heroin addicts patients treated by methadone in the city of Tangier. On the other hand, the improvement of the qual- 
ity of life of Moroccan patients remains far overshadowed by other difficulties, such as the persistence of the stigmatizing vision of society and the rights marginalizing, the economic situation of the country which limits the possibilities of professional insertion although this situation is being improved with a strong economic growth. As for the other countries, the Morocco must improve this program and have more interest in this subject because of the increase in the rate of morbidity of patients and of polydrug use. In practice, efficiency of program of maintenance by methadone also depends on the skills and the attitude of the professionals of the Institutes of support and rehabilitation, also on the specific characters of the patient, as well as the sociocultural context.

\section{References}

Ball, J. C., \& Ross, A. (1991). The Effectiveness of Methadone Maintenance Treatment. New-York: Springer-Verlag. https://doi.org/10.1007/978-1-4613-9089-3

Fullerton, C. A., Kim, M., Thomas, C. P., Lyman, D. R., Montejano, L. B., Dougherty, R. H., \& Delphin-Rittmon, M. E. (2014). Medication-Assisted Treatment with Methadone: Assessing the Evidence. Psychiatric Services, 65, 146-157.

https://doi.org/10.1176/appi.ps.201300235

General Accounting Office. (1990). Methadone Maintenance-Some Treatment Programs Are Not Effective. Creator federal Oversight Needed. GAO/HRD-90-104. Washington DC: Superintendent of Documents, U.S. Government.

Giroux, C. (1999). L'utilisation de la méthadone dans la réadaptation des personnes narcomanes. Québec: Médication Enr.

Guignard, R., Beck, F., \& Obradovic, I. (2011). Prise en charge des addictions par les médecins généralistes. In A. Gautier (Ed.), Baromètre santé médecins généralistes 2009 (pp. 177-201). Inpes, coll. Saint-Denis: Baromètres santé.

Karila, L., Coscas, S., Lecacheux, M., Noble, F., Legleye, S., Beck, F., Dupont, P., Benyamina, A., Karmous, R., \& Reynaud, M. (2008). Conduites Addictives. EMC, France, 1-12.

Lalande, A., \& Grelet, S., Eds. (2001). Tensions et transformations des pratiques de substitution en ville: suivi des patients usager de drogues en médecine générale (approche qualitative). Paris: OFDT.

Mark, W., \& Parrino, M. P. A. (1992). President American Methadone Treatment Association. New York: INC.

Mark, W., \& Parrino, M. P. A. (1993). Current Treatment Realities and Future Trends. State Methadone Treatment Guidelines: A Treatment Improvement Protocol. Rockville: DIANE Publishing Company.

Mattick, R. P., Breen, C., Kimber, J., \& Davoli, M. (2009). Methadone Maintenance Therapy versus No Opioid Replacement Therapy for Opioid Dependence. Cochrane Database of Systematic Reviews, CD002209, 3. https://doi.org/10.1002/14651858.CD002209.pub2

Millson, P. E., Challacombe, L., Villeneuve, P. J., Fischer, B., Strike, C. J., Myers, T., \& Pearson, M. (2004). Self-Perceived Health among Canadian Opiate Users: A Comparison to the General Population and to Other Chronic Disease Populations. Canadian Journal of Public Health, 95, 99-103.

Observatoire français des drogues et des toxicomanies. (2003). Substitution aux opiacés, synthèse des informations disponibles de 1996 à 2001 en France. Paris: OFDT.

Programme de maintenance à la méthadone au Maroc. (2008). Rabat: ministère de la 
santé Direction d'épidémiologie et la lutte contre les maladies.

Salhi, Y. (2011). Traitement de substitution des opiacés par la méthadone. Évaluation à Mi-parcours expérience de Tanger. [Mémoire de diplôme universitaire d'addictologie] Rabat: Université Mohammed V, Souissi faculté de médecine.

Taïeb, O. (2006). Les histoires des toxicomanes. Narrations et lectures dans les addictions. [Thèse de doctorat d'Université, Psychologie] Paris: Université Paris XIII.

Teoh Bing Fei, J., Yee, A., Bin Habil, M. H., \& Danaee, M. (2016). Effectiveness of Methadone Maintenance Therapy and Improvement in Quality of Life Following a Decade of Implementation. Journal of Substance Abuse Treatment, 69, 50-56. https://doi.org/10.1016/j.jsat.2016.07.006

Zweben, J. E., \& Payte, J. T. (1990). Methadone Maintenance in the Treatment of Opioid Dependence. A Current Perspective. Western Journal of Medicine, 152, 588-599. 